\title{
Evaluating The Effectiveness Of Audio In Hybrid Courses
}

Daniel R. Ball, Ph.D., Monmouth University, USA

Joseph B. Mosca, Ed.D., Monmouth University, USA

David P. Paul, III, Ph.D., Monmouth University, USA

\begin{abstract}
The prevalence of either completely online or hybrid courses has continued to increase over the past decade, but properly designing the delivery mode of these courses remains a challenge. Whereas fully online institutions of higher education may focus on a purely online delivery format, more traditional colleges and universities have the challenge of balancing online and traditional classroom instruction using the hybrid course format. Whereas basic hybrid courses may have relied more on visual aids of instruction, this paper focuses on the effectiveness of enhancing these hybrid courses with audio lectures. Hybrid courses were created using PowerPoint slides consisting of a mix of visual and audio instructional delivery modes, and student surveys were subsequently administered at the conclusion of the semester to determine the ultimate effectiveness of audio enhancements. This paper presents the details of this case study, the corresponding statistical analyses and interpretations, and general concluding recommendations for audioenhanced course design. Overall, the addition of the audio component to the hybrid course structure made the hybrid course experience more effective, increased the likelihood that the students would take or recommend future hybrid courses that contained audio enhancements, and made it more likely that the students would prefer a hybrid course to a traditional classroom-only course. Continued research is necessary to provide a more active learning experience and class community during the online components, and synergistically utilize classroom time more effectively to truly capture the benefits of both online and traditional instruction using the audioenhanced hybrid course format.
\end{abstract}

Keywords: Hybrid Courses; Audio Lectures; Online Education; Hybrid Course Design

\section{INTRODUCTION}

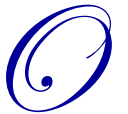

nline instruction has continued to evolve over the years, and currently this mode of instruction has become a major part of higher education (Hiltz and Turoff, 2005; Terry, 2007). Terry (2007) cites that the Department of Education estimates an increase of 100 college courses are added to an online format each month. There are some advantages to the online mode, as it partially replaces classrooms and allows students to work at their own pace. However, there can also be significant drawbacks if the instructor lacks sophistication and creativity in creating the online lessons and one must get accustomed to creating an online lesson that does not merely follow the more traditional lecturing format. One solution to this problem is to utilize the newer hybrid (i.e., blended) course format. As this trend for more online/hybrid courses continues, Hiltz and Turoff (2005) go as far as to propose that the tens of thousands of traditional local, regional, and national universities may ultimately be replaced by only a few hundred online/hybrid "mega-universities".

The average 3 -credit course consists of 1.25 contact hours twice a week, or once a week for 2.50 contact hours; both for a 15-week semester. When constructing a hybrid (i.e., blended) course which requires that classroom time is reduced by half, the instructors need to re-examine what teaching techniques are most appropriate for the new teaching format. What this task entails is an entirely new course design (Bates and Watson, 2008), which has been hypothesized to "provide moderate-to-high degrees of access and flexibility while offering the potential for moderate-to-high dialogue and low-to-moderate structure" (Millison and Wilemon, 2008). Graduate 
students and working professionals who are limited in classroom time can benefit from hybrid courses and, at the same time, reap the benefits of classroom interactions (Millison and Wilemon, 2008). So, in essence, a properly designed hybrid course may offer the students the "best of both worlds": effective flexibility and technologyenhanced online instruction coupled with carefully planned classroom interactions.

The traditional method of teaching a course involves the instructor transmitting knowledge and information to the students. The instructors spend a considerable amount of time developing lecture materials in an attempt to enhance the material to maintain student focus and spark interest. This approach is called "face-to-face" teaching and is familiar to students because of its use in grades K-12. Another term for "face-to-face" instruction is "direct instruction". A lecture can be called a "direct format approach to teaching" where the teacher tells the learner what they need to know. Yelon (2006) sites Clark (2001) and introduces "guided discovery". In the guided discovery approach, students learn on their own by observing, asking questions, and conducting activities, all of which are coupled by feedback from the instructor (Yelon, 2006). The guided discovery approach is a preferred approach for hybrid courses because it allows students to learn on their own by observing, and we believe enhancing the observations with audio explanations increases the student's ability to learn, comprehend, and retain; thus closing the potential learning gaps between traditional classroom and pure online instructions. What these researches have observed from the guided discovery approach is that students can learn at their own pace and can review the material as they see fit.

This paper extends the previous work by Mosca et al. (2010) by now incorporating a detailed study that evaluates the enhancement of hybrid course structures and effectiveness using this audio aid. This revised study specifically focuses on designing hybrid courses with audio enhancements, and presents surveyed results describing how students relate to these audio-enhanced hybrid classes. Audio lectures were added to the PowerPoint slides that further explained what appeared on the slides and, at times, asked questions that respond when the student advances the slide by clicking the mouse. Therefore, visual aids, audio instruction, and interactive learning were incorporated in the hybrid courses analyzed in this study.

\section{A REVIEW OF THE LITERATURE}

The key areas to consider in this research effort pertained to the evolution of hybrid leaning modes, the proper design of hybrid/blended courses, and the potential impacts of enhancing online instruction using audio components. According to Jackson and Helms (2008), today's students have grown up with the Internet, iPods, and text-messaging. In many cases, podcasts have been used to supplement traditional lectures and may offer the student the ability to enhance study efforts with the convenience of portability (Robinson and Ritzko, 2009). Bongey, Cizadlo, and Kalnbach (2006) caution, however, that podcasts may serve as good supplements to actual classroom lectures, but not as suitable replacements and many students are tempted to stop attending class altogether because of this option. However, the proper usage of this technology as an in-class supplement or to enhance online education may be effectively employed.

Therefore, due to the high technological literacy of today's students, hybrid courses are easy for students to adapt to because, within their culture of instant gratification, they can get immediate feedback on assignments when enrolled in a hybrid course. Some other advantages are: reduced time in the classroom, less travel expenses, more course availability because additional class(es) can be taken simultaneously, and more flexibility for students to complete work at their own pace. In addition, it has been reported that more than half of all colleges find online learning essential for their institutions, and that online course enrollment has increased by 33\% (Jackson and Helms, 2008).

El Mansour, Mupinga, and Davidson (2007) explain how many terms there are for online instruction such as: e-learning, internet learning, distributed learning, network learning, tel-learning, virtual learning, or web-based learning. All of these terms relate to an instructional mode whereby the learner is geographically separated from the instructor, and some of the lessons are online and some are face-to-face. Depending on the creativity of the instructor, the online delivery can be composed of a combination of audio, video, color, graphics, and animation. All of these delivery methods, when used properly, can stimulate the learner and help the student maintain focus. There seems to be a move towards online instructions of all varieties; overall online enrollment has increased from 1.98 million in 2003 to 2.35 million in 2004 (El Mansour, Mupinga and Davidson, 2007). 
Hiltz and Turoff (2005) define the following driving societal forces that support online learning:

- $\quad$ Flexibility that the learners have to be able to incorporate education with life and employment;

- The learning effectiveness of blended courses being equal to, or sometimes better than, direct face-to-face instruction; and

- $\quad$ Blended and all online courses keep colleges and universities competitive.

According to D'Orsie and Day (2006), the following ten guidelines can assist in the design of hybrid/blended courses:

- $\quad$ Identify all the prerequisites the students will require before taking the course.

- $\quad$ Clarify the computer requirements and capacity for the user.

- $\quad$ Establish a support system for students to obtain help when needed, such as a "Help Desk."

- The instructor must be specific as to how tests will be taken by the students, defining if tests will be online or in the classroom.

- The instructor, without provocation, must define the policies for the course such as: when the last day is to register for the course or the attendance rules.

- What are the participation policies?

- $\quad$ A course schedule must be designed depicting what will take place during classroom time.

- One must keep in mind that the time spent in the classroom will be cut in half; therefore, effective time management becomes imperative.

- When a class roster is available, it is helpful for the instructor to e-mail the students welcoming them and providing a general idea as to what will be taking place.

- $\quad$ Begin to build an online community by sharing the e-mail addresses.

Improving on traditional classroom instruction by adding audio supplements may be another teaching option. Peterson et al. (2006) talk about assessment techniques and learning, and also how instructors can implement approaches for quality teaching and learning. These strategies can be applied to audio-enhanced hybrid course construction by addressing the following questions:

- What were you thinking when you saw this slide?

- What did you learn from the audio enhancement?

- What do you remember from the audio portion?

- What more did you learn by the audio explanation?

- How can you use what you learned?

It has been mentioned in the literature how hybrid courses may contain graphics and videos, thus incorporating both audio and visual components. Penrose (2006) points out that some students prefer learning through visualization, and goes on to say that many learn effectively through a combination of verbal and visual approaches. Penrose's list of how to use visualization in hybrid course design includes the following:

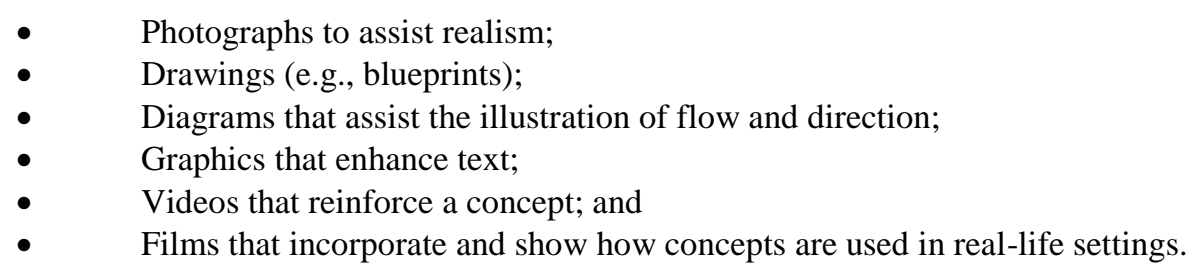

It has been found that when audio is incorporated into online courses, it is usually in the form of narration, and can be in the forms of music and sound effects. When audio is combined with visual media, graphics, and animation, audio enhancement is most beneficial for the learner for retention and the gaining of knowledge. The greatest influence on the choice to incorporate audio is intuitive as to where the audio is most effective, and the 
length of the audio segment can range from 60 seconds on up; however, as audio time increases, attention span decreases (Calandra, Barron, and Thompson-Sellers, 2008). According to Rosebush (1992), when teaching a History class he used the Ninth Symphony as a scaffold from which to view European social and cultural history in the first quarter of the nineteenth century, and offered his students the ability to relate through the use of musical passages so students could listen to the audio while reading the written material online (Rosebush, 1992).

Antonucci (2008) explains that memory refers to one's long-term knowledge of word and object meaning. There is increasing evidence that, rather than the effective domain being a passive warehouse of knowledge, semantic memory is a dynamic system and the effectiveness relies on the coordination of multiple components distributed across a large network of cortical regions. These multiple components include audio, visual, tactual, and practice to mention a few. In a study conducted by Valentine, Hedrick, and Swanson (2006), the effect of an auditory training program was examined, Fast ForWord Language, with 26 students ages 7-10 years old. As two subgroups based on reading ability, all students received six weeks of intervention with audio. Participants showed increases in language skills and in phoneme awareness after the intervention of audio enhancement.

According to Willems, Ozyurek, and Hagoort (2008), understanding language always occurs within a situational context, as a result of combining streams of information from different domains and modalities. An example of combining streams of information is that of spoken language and visual information, which are perceived together, therefore, when the learner is viewing contents and listening to an explanation of the viewed contents, the combination is a support mechanism that reinforces learning. Their study adds to the growing insight that the language system incorporates information coming from linguistic and extra linguistic domains with the same neural time course and by recruitment of overlapping brain areas; therefore, learning is made easier.

Due to the variety of learning styles and technology-based teaching aids now available, Mossavar-Rahmani and Larson-Daugherty (2007) encourage the use of a multi-modal instructional approach using visual, audio, and interactive methods of online instruction to complement the face-to-face classroom meetings. This paper extends both the traditional online and visual hybrid teaching approaches by utilizing the strong evidence presented in this literature review that incorporating linguistic features through the audio components can enhance the overall visually-based hybrid instruction mode.

\section{THE METHOD}

This current research effort used the guided discovery approach through the design of interactive, animated presentation slides that have been enhanced with audio lectures. The media used for this study were animated PowerPoint slides whereby the learner had to advance the PowerPoint slides by clicking the mouse to advance the text on each slide, and the accompanying audio lecture would play automatically (with student options to stop/pause/rewind/etc.). For example, the slide content might contain the following:

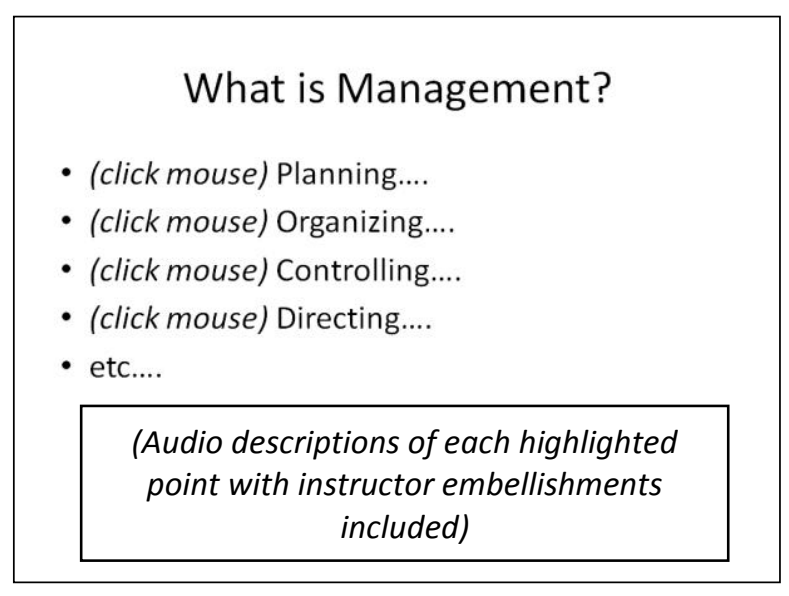


As one can note from the above example slide, the student can visually study the slide content but must also interact with the media to facilitate the learning process. Therefore, the responsibility for learning is with the student. It must be kept in mind that the instructor preparing the online lessons should take responsibility for teaching the concepts in a comprehendible fashion that will maintain the students' focus, and the audio embellishments may be used to add further explanations and examples to enhance the written slide content.

This study was conducted at a private university in the eastern part of the United States. The institution is medium in size with a total enrollment of approximately 5,800 students, of which 1,200 are graduate students. This university is classified as a comprehensive teaching institution. The purpose of this study was to determine student satisfaction when attending a hybrid course that has been enhanced with audio lectures by answering the following questions:

1) How many hybrid courses have you completed prior to this course?

2) Was there an audio component to the prior hybrid course(s)?

3) Did the audio component make the hybrid experience more effective than without audio?

4) Could you effectively follow the audio presentations?

5) How well were the audio clips synchronized with the oral and video presentations?

6) Have you ever had an online oral lesson?

7) Could you effectively follow these oral presentations?

8) How well were the video clips synchronized with the oral presentations?

9) Did you feel that you had adequate access to the professor?

10) How effective was the discussion while not in the classroom?

11) Was your interest maintained while not in the classroom?

12) Did you have the sense of a student community while not in the classroom?

13) Where did you gain access to the internet?

14) How effective was the classroom lecture?

15) On the day that the class meets, would you prefer: (a) more lecture time, (b) the same amount of lecture time, or (c) less lecture time?

16) On the day the class meets, would you prefer: (a) more student presentation time, (b) the same amount of student presentation time, or (c) less student presentation time?

17) Would you like short case analyses to be part of the class time?

18) Would you like problem solving exercises to be part of the class time?

19) Would you like open discussion with the professor to be part of the class time?

20) Would you take another hybrid course?

21) Did the inclusion of an audio component to this course affect your decision to take or recommend future hybrid courses in Question \#20?

22) Would you prefer that this course was hybrid or traditional?

23) Did the inclusion of an audio component to this course affect your preference of hybrid or traditional courses in Question \#22?

24) In a hybrid course, do you like the flexibility of choosing when and how quickly you learn material?

25) In your opinion, what is the minimum level for a hybrid course structured like this one (i.e., with audio): (a) 100 level (i.e., freshman), (b) 200 level (i.e., sophomore), (c) 300 level (i.e., junior), (d) 400 level (i.e., senior), (e) graduate level, or (f) hybrid courses should not be offered?

26) Does the inclusion of audio in a hybrid course impact your selection for the minimum level necessary to take a hybrid course in Question \#25?

This survey was conducted in two phases:

1) Phase 1: An initial round of surveys was administered to 145 students to gauge general satisfaction of hybrid courses, the preference of including an audio component, the quality of the prepared audio presentations, the level of student interest maintained while not in the classroom, and the students' preference of controlling the pace of learning. 
2) Phase 2: Based on favorable findings of Phase 1, the surveys were administered to a total of 212 students distributed according to the following class levels: 29 sophomores, 129 mixed juniors/seniors, 22 seniors, and 32 graduate students. A complete tabulation of survey results for each question, including graphical representations of the results, is available from the authors.

\section{STUDY RESULTS}

This section contains the results of preliminary surveys and hypothesis testing to gauge initial responses to the audio-enhanced hybrid course structure (i.e., Phase 1), and then a second round of testing with more detailed statistical analyses and hypothesis testing (i.e., Phase 2). Details concerning Phase 2 testing and hypothesis testing are available from the authors.

\section{Phase 1}

The preliminary results from the Phase 1 testing were analyzed according to the following hypothesis tests:

Hypothesis 1: The majority of students are satisfied with hybrid courses.

Hypothesis 2: Students find that courses with audio enhancement are more effective.

Hypothesis 3: Audio enhanced hybrid courses can be effectively followed.

Hypothesis 4: Interest was maintained while not in the classroom environment.

Hypothesis 5: Students prefer the flexibility of choosing when and how quickly they learn material.

In examining Hypothesis 1 - "The majority of students are satisfied with hybrid courses" - it was determined that 116 of $145(80 \%)$ students responded to "would you prefer that the course be hybrid or traditional", indicated a preference for hybrid courses in the future. This distribution of responses was tested by a Chi-Squared test. These results clearly indicate satisfaction with the hybrid course format $\left(\chi^{2}=145.834\right.$, $\left.\mathrm{df}=2, \mathrm{p}=0.000\right)$. Hypothesis 1 is supported: students responding were clearly satisfied with a hybrid course format.

In examining Hypothesis 2 - "Students find that courses with audio enhancement are more effective" - we found that 73 of $145(50.3 \%)$ students responded that the audio component strongly agreed, and another $21(14.5 \%)$ agreed that the audio component made the hybrid experience more effective than without an audio component. This distribution of responses was tested by a Chi-Squared test. The results clearly indicate that students found audio enhancement of hybrid courses to be effective $\left(\chi^{2}=61.667\right.$, $\left.\mathrm{df}=3, \mathrm{p}=0.000\right)$. In addition, $53.8 \%$ of those responding indicated that their preference would be for the hybrid course to have an audio component. Hypothesis 2 is therefore strongly supported.

In examining Hypothesis 3 - "Audio enhanced hybrid courses can be effectively followed" - we found that 94 of $145(64.8 \%)$ of students responding felt that they could follow hybrid course audio presentations very well, and an additional $35(24.1 \%)$ felt that they could follow such presentations well. This distribution of responses was tested by a Chi-Squared test. The results clearly indicate that students could effectively follow the audio presentation $\left(\chi^{2}=121.724, \mathrm{df}=4, \mathrm{p}=0.000\right)$. Hypothesis 3 is therefore strongly supported.

In examining Hypothesis 4 - "Interest was maintained while not in the classroom environment" - we found that 58 of $145(40 \%)$ definitely agreed with this statement, while an additional 66 (45.5\%) moderately agreed, 18 (12.4\%) fairly agreed, and only $3(2.1 \%)$ poorly agreed. This distribution of responses was tested by a Chi-Squared test. The results clearly indicate that students' interest was maintained while not in a classroom environment $\left(\chi^{2}=\right.$ $77.152, \mathrm{df}=3, \mathrm{p}=0.000$ ). Hypothesis 4 is therefore strongly supported.

In examining Hypothesis 5 - "Students prefer the flexibility of choosing when and how quickly they learn material" - we found that 144 of $145(99.3 \%)$ agreed with this statement. A Student's t test was used to examine 
this difference. The results of this test confirmed the obvious, that students overwhelmingly and significantly preferred the flexibility of choosing when and how quickly they learn material $(\mathrm{t}=289.000, \mathrm{df}=144, \mathrm{p}=0.000)$. Hypothesis 5 is therefore strongly supported.

\section{Phase 2}

Based on the success of the Phase 1 survey results, the surveys were administered again and the Phase 2 results were analyzed more closely using the following categories: (1) overall effectiveness of audio component and preference for hybrid courses; (2) quality and effectiveness of online component; and (3) class time design. A summary of the key findings for each category is presented below.

\section{Overall Effectiveness of Audio Component and Preference for Hybrid Courses (Questions 1-3, 20-26)}

The initial portion of Phase 2 of this study addressed the overall effectiveness of the hybrid course experience and, in particular, how this experience was affected by the addition of an audio component to its structure. The initial questions were used to isolate the students that had taken a prior hybrid course(s) and determine the direct impact of the audio component on its effectiveness (Questions 1-3). Based on the results of Question 3, the majority of students at every class level answered "strongly yes" or "yes" regarding whether the inclusion of audio enhanced the effectiveness of the hybrid course structure. This result is consistent with that determined when testing Hypothesis 2 in Phase 1 of this study.

With this overall increased effectiveness using audio enhancements, students were asked to evaluate their preference in comparison to a traditional course. Based on the results of Question 22, at least $75 \%$ of the respondents in each class level (and 100\% at the senior level) preferred the hybrid course structure to a traditional course. This result supports those found when testing Hypothesis 1 in Phase 1 of this study. Furthermore, with the exception of the graduate class level, the majority of the students indicated that this preference was directly affected by audio enhancements (Question 23). This positive response increased from 53.57\% at the sophomore level to $100.00 \%$ at the senior level, but declined to only $43.75 \%$ at the graduate level. In addition to the specific course taken, the majority of respondents (at least $82.76 \%$ at the sophomore level and up to $100.00 \%$ at the senior level) would take another hybrid course in the future (Question 20). With the exception of the graduate class level, the majority of students indicated that they would be more likely to take a future hybrid course based on the addition of the audio component (Question 21). This positive response increased from 65.52\% at the sophomore level to $100.00 \%$ at the senior level, but declined to only $46.88 \%$ at the graduate level.

The overall increase of students that are influenced positively by the addition of the audio component based on the respective undergraduate class level (Questions 21 and 23) may be due in part to the students' increased confidence with utilizing technological aids as they progress through the program. Graduate students, however, may have developed more independent work habits and, although will still benefit from the addition of an audio component, are not as influenced as students at the undergraduate level.

In general, the overall feeling was nearly unanimous at all class levels that students prefer the flexibility of choosing when and how quickly they learn the material (Question 24); this result compares consistently with that of Hypothesis 5 in Phase 1 of this study. The majority of the class levels responded that audio-enhanced hybrid courses should not be offered until the sophomore class level (Question 25). Based on the response from Question 26 , the majority of all respondents did not believe that adding audio to the hybrid course structure had any influence on this minimum class level.

Quality and Effectiveness of Online Component (Questions 4-13)

The second portion of Phase 2 of this study addressed the overall quality and effectiveness of the online instructional component. The overall goal of these questions was to help determine the quality of the hybrid design with audio enhancements. 
For this portion of the survey, one of the main concerns was whether or not the audio component could be followed and effectively integrated into the hybrid structure. For all class levels (i.e., sophomore, mixed junior/senior, senior, and graduate), the majority of the students responded either "very well" or "moderately well" regarding: the effective following of the audio presentations (Question 4: at least 78\% in all classes, and 100\% of seniors); adequate synchronization of audio and oral/video presentations (Question 5: at least 75\% in all classes, and $100 \%$ of seniors); the ability to effectively follow the oral presentations (Question 7: at least $71 \%$ in all classes, and $100 \%$ of seniors); and the proper synchronization of video clips with oral presentations (at least $56.25 \%$ in all classes, and $100 \%$ of seniors). Questions 4, 5, 7, and 8 especially support the preliminary Phase 1 hypothesis testing that the audio-enhanced hybrid courses could be effectively followed (i.e., Hypothesis 3 of Phase 1).

One of the biggest challenges when creating a hybrid course is facilitating effective discussions outside of class time (Question 10), maintaining student interest while not in the classroom (Question 11), and creating a sense of a student community while not in the classroom (Question 12). During Phase 2 of this research study: at least $84 \%$ of all respondents (and 100\% of seniors) reported that online discussions were either "very effective" or "moderately effective" (Question 10); at least 75\% of the students at all levels (and 100\% of seniors) responded that interest was either "definitely" or "moderately" maintained outside the classroom (Question 11); and at least 55\% of all students (and 100\% of the seniors) answered "strongly yes" or "yes" when asked if there was a sense of student community outside of the classroom (Question 12). Based on these results and the Phase 1 hypothesis testing (i.e., Hypothesis 4), these issues seemed to be addressed adequately, especially the development of an online student community.

The prior online course experience of all students was mixed, with only the senior level class having had all respondents taken an online/hybrid course before (Question 6). Furthermore, the majority of the students believed that they had adequate access to the professor during the course (at least 93\% responded "yes" or "maybe" to Question 9). Question 13 really shows the diversity in where students can gain access to the Internet for the purposes of conducting coursework. Therefore, the prior experience, student-instructor interactions, and Internet access should not have been a factor in determining the student success when the hybrid courses were enhanced with audio for this particular study.

\section{Class Time Design (Questions 14-19)}

This third portion of the study was intended to provide some insights into how to better plan and use the classroom meeting time and, conversely, what types of content can be presented in the online component. It should be noted that these survey responses are very much dependent on the individual course design that the professor(s) of these courses employed.

In general, the students believed that the classroom lectures were either "very effective" or "moderately effective" (Question 14; greater than 93\% respondents in all classes, and 100\% in both the sophomore and senior classes). The results to Questions 15, 16, 17, and 18 all indicate that the students prefer a more hands-on approach to classroom utilization orientation, with active learning exercises. Given that the lectures were placed online and augmented with audio components, the students generally recommended that the in-class time would be better utilized with either "the same amount" or "less" lecture (Question 15; between $81 \%$ and $100 \%$ of responders), "more" or "the same" student presentations (Question 16; between 71\% and 100\%), short case analyses (Question 17; between 65\% and 100\%), problem solving exercises (Question 18; between 65\% and 100\%), and open discussion with the professor (Question 19; between 93\% and 100\%). It is therefore recommended that instructors utilize the classroom time in more engaging active learning efforts, with minimal repeat of the online audioenhanced lectures.

\section{Statistical Significance of Overall Assessment: Phase 2 Results}

Finally, comprehensive statistical analyses using additional hypothesis testing were conducted to determine the overall effectiveness, and student preferences and future opinions regarding the inclusion of audio components in hybrid courses. For each of these analyses, a null hypothesis $\left(\mathrm{H}_{0}\right)$ was compared to an alternative hypothesis $\left(\mathrm{H}_{1}\right)$ using a Chi-Squared analysis and assuming a baseline level of significance of $\alpha=0.05$. Therefore, any findings 
where the observed Chi-Squared value was greater than or equal to the critical value (based on the corresponding degrees of freedom and level of significance) would allow the null hypothesis to be rejected, thus indicating that there would be a maximum probability of 0.05 of achieving a Type I Error (i.e., falsely rejecting the null hypothesis and accepting the alternative position). To determine the Chi-Squared values for each testing scenario, the observed survey results were compared to an expected value based on the assumption that there was indifference between each of the possible answer choices; therefore, the average number of responses was chosen as the expected frequencies for each possible response. Testing was conducted individually for the sophomore, junior/senior, senior, and graduate class levels, as well as a total comprehensive analysis for these class levels combined. Furthermore, testing included analyses pertaining to each of the survey options in addition to more segmented option groupings. Complete tabulations of these analyses are available from the authors.

The first analysis was performed to determine the statistical significance of the survey results for Question 3 when considering the following hypotheses:

$\mathbf{H}_{\mathbf{0}}$ : There is no general opinion of the students regarding the effectiveness of incorporating an audio component to hybrid courses.

$\mathbf{H}_{1}$ : According to the student surveys, the inclusion of an audio component makes the hybrid experience more effective than without audio.

When analyzing Question 3, the overall results for all class levels combined clearly indicated that the null hypothesis could be rejected with $\alpha=0.05$, which indicates that the students do have a statistically significant opinion that the inclusion of an audio component does make the hybrid course experience more effective than a traditional hybrid structure without audio. In order to get a better measure, the hypothesis testing was repeated when omitting the responses that were not applicable (i.e., "N/A") and comparing the grouped responses of "Strongly Yes" and "Yes" with the grouped responses of "Maybe" and "No". Even with these more concise groupings, the results of the hypothesis testing indicate that the null hypothesis can be rejected with a level of significance of $\alpha=$ 0.05; thus further suggesting the positive effect of incorporating an audio component into the hybrid course structure. Furthermore, when breaking down the survey responses by class, the only class that did not reject the null hypothesis at a level of significance of $\alpha=0.05$ was the sophomore class. This result may likely be due to the small number of students that were eligible after eliminating the "N/A" responses (i.e., only eight responders remained), and the positive effect of adding audio components to the hybrid course structure was still accepted at a level of significance of $\alpha=0.158$.

The second analysis was performed to determine the statistical significance of the survey results for Question 21 when considering the following hypotheses:

$\mathbf{H}_{\mathbf{0}}$ : The inclusion of an audio component had no effect on a student decision to either take or recommend a future hybrid course.

$\mathbf{H}_{1}$ : The inclusion of an audio component did make the student more likely to take or recommend a hybrid course in the future.

When analyzing Question 21, the overall results for all class levels combined clearly indicated that the null hypothesis could be rejected with $\alpha=0.05$, which indicates that the students do have a statistically significant opinion that the inclusion of an audio component will encourage them to either take or recommend a hybrid course in the future that includes audio delivery technologies. In order to get a better measure, the hypothesis testing was repeated by isolating the response "Yes, I am more likely to take a hybrid with audio" from all other responses. Even with this isolated response, the results of the hypothesis testing indicate that the null hypothesis can be rejected with a level of significance of $\alpha=0.05$ for the combined total of all class levels, as well as the individual groupings of junior/senior and senior classes. The sophomore class level also responded that the audio component would encourage them to either take or recommend hybrid courses based on the audio inclusion at a level of significance of $\alpha=0.095$ (i.e., only a $9.5 \%$ chance of falsely rejecting the null hypothesis). However, the graduate class level 
would only reject the null hypothesis at a level of significance of $\alpha=0.725$, which is not favorable. When looking closer at the data, however, this response is not directed negatively at the inclusion of the audio component because all of the other responses were in the category of "No, I would take a hybrid even if it did not have audio"; thus continuing to suggest the preference of the hybrid course structure at the graduate class level. In fact, of the 32 responders, 15 were now suggesting that they would take or recommend a hybrid course based on the inclusion of the audio component; and all 32 now prefer the hybrid course structure overall.

The third analysis was performed to determine the statistical significance of the survey results for Question 23 when considering the following hypotheses:

$\mathbf{H}_{\mathbf{0}}$ : The inclusion of an audio component had no effect whether or not a student prefers the specific course to consist of a hybrid or traditional course structure.

$\mathbf{H}_{1}$ : The inclusion of an audio component did make the students prefer that the course be a hybrid course instead of the traditional course structure.

When analyzing Question 23, the overall results for all class levels combined indicated that the null hypothesis could be rejected with $\alpha=0.05$, which indicates that the students do have a statistically significant opinion that prefers the specific course where the survey was administered to be of a hybrid structure based on the inclusion of an audio component. This result remains even when the positive answer is isolated against the groupings of all other possible answers. However, there is less support of the hybrid structure when considering only the sophomore or graduate class levels as hypothesis testing only allowed the rejection of the null hypothesis in these classes at a level of significance of $\alpha=0.706$ and $\alpha=0.480$, respectively. Based on the previous analyses, it appears as though the audio component is well received and significantly aids in the hybrid course structure. The approvals of these specific courses may not be as significant at the sophomore level due to the students' overall academic inexperience and at the graduate level simply because the graduate students generally prefer the hybrid course structure regardless of the audio enhancements.

\section{CONCLUSIONS}

This paper presented a student-centered case study analysis to determine the effects of enhancing hybrid courses with audio content. Surveys were created and administered to classes consisting of sophomores, mixed juniors/seniors, seniors, and graduate students, and the study was then conducted in two phases. Phase 1 helped establish the overall students' views pertaining to audio-enhanced hybrid courses, and Phase 2 consisted of larger student sample sizes and more detailed statistical analyses of the survey results. Overall, the addition of the audio components to the hybrid course structure was very well received by the students at each class level. Based on the survey results, the general consensus for all questions pertaining to the audio components seemed to be very favorable and suggest that audio technologies can provide improvements over the previous hybrid and traditional course structures. Whereas sophomores were generally the least likely to succeed with the hybrid format, seniors overwhelmingly preferred the hybrid course structure. This result is likely due to a variety of factors including the natural academic maturing and ability to work more independently at the senior level, increased comfort with technological learning aids, and also greater exposure to prior hybrid courses. Graduate students especially like the flexibility that hybrid courses offer, and the audio component helps to convey the course content better than a strictly visual format.

Overall, the addition of the audio component to the hybrid course structure made the hybrid course experience more effective, increased the likelihood that the students would take or recommend future hybrid courses that contained audio enhancements, and made it more likely that the students would prefer a hybrid course to a traditional classroom-only course. Given these research results, it is essential that the instructor properly design the audio components of the course. As suggested by the survey results, audio technologies can enhance the online content delivery and limit the necessity for classroom lectures, thus allowing for more active learning approaches when the class physically meets. Continued research is necessary to provide a more active learning experience and class community during the online components, and synergistically utilize classroom time more effectively to truly capture the benefits of both online and traditional instruction using the audio-enhanced hybrid course format. 


\section{AUTHORS INFORMATION}

Daniel R. Ball, Ph.D.: Daniel R. Ball is currently an Assistant Professor at Monmouth University. Dr. Ball holds a Ph.D. in Industrial Engineering \& Operations Research from the University of Massachusetts Amherst, M.S. degrees in Management from Rensselaer Polytechnic Institute and Civil Engineering from Lehigh University, and a B.S. degree in Mechanical Engineering from Western New England University. His teaching and research interests include technology and operations management, real options, risk-based distributed decision-making, the modeling and simulation of complex systems, modeling for comprehensive organizational sustainability, and technologicallyenhanced teaching methods. Prior industrial experiences include working as a design engineer and project manager in the environmental consulting industry. E-mail: dball@monmouth.edu (Corresponding author)

Joseph B. Mosca, Ed.D.: Dr. Joseph B. Mosca, Associate Professor and Chair of the Department of Management and Decision Sciences in the Leon Hess Business School at Monmouth University earned his doctorate at New York University. Dr. Mosca specializes in Human Resource management, Human Relations, and active teaching methods, and is the recipient of seven teaching awards and three distinguished paper awards. His current research interests focus on developing hybrid courses, employee behavior, and jobs in the $21^{\text {st }}$ Century. E-mail: mosca@monmouth.edu

David P. Paul, III, D.D.S., Ph.D.: Following a 23 year career practicing dentistry, Dr. Paul is currently Associate Professor of Marketing and Health Care Management and Coordinator of the Graduate Concentration in Health Care Management at Monmouth University. He has published over 100 refereed publications in such journals as Health Marketing Quarterly, the Journal of Hospital Marketing, Hospital Topics, the International Journal of Medical Marketing, Clinical Research and Regulatory Affairs, the Marketing Management Journal, the Journal of NonProfit and Public Sector Marketing, the Journal of Consumer Marketing, and the Journal of the American Dental Association, as well as numerous regional, national and international conference proceedings. E-mail: dpaul@monmouth.edu

\section{REFERENCES}

1. Antonucci, Sharon M., and Reilly, Jaimie, (2008). "Semantic Memory and Language Processing: A Primer," Seminars in Speech and Language, Department of Speech-Language Pathology and Audiology, New York University, Feb, Volume 29, Number 1, pp. 5-17.

2. Bates, Constance, and Watson, Maida, (2008). "Re-learning Teaching Techniques to be Effective in Hybrid and Online Courses," Cambridge, Hollywood: Journal of American Academy of Business, Volume 13, Issue 1, pp. 38-44.

3. Bongey, Sarah Bryans, Cizadlo, Gerald, and Kalnbach, Lynn, (2006). "Explorations in Course-Casting: Podcasts in Higher Education," Campus-Wide Information Systems, Volume 23, Number 5, pp. 350-367.

4. Calandra, Brendan, Barron, Ann E., Thompson-Sellers, Ingrid, (2008). "Audio Use in E-Learning: What, Why, When, and How?” International Journal on E-Learning, Volume 7, Number 4, pp. 589-601.

5. Clark, Lawrence J., (2001). “Web-based Teaching: A New Educational Paradigm,” Intercom, Volume 48, pp. 20-21.

6. D'Orsie, Sharon M., and Day, Karen, (2006). “Ten Tips for Teaching a Web Course," Tech Directions, Feb, Volume 65, Issue 7, pp. 18-20.

7. El Mansour, Bassou, and Mupinga, Davison, M., (2007). "Students' Positive and Negative Experiences in Hybrid and Online Classes," College Student Journal, March, Volume 41, Number 1, pp. 242-248.

8. Hiltz, Starr Roxanne, and Turoff, Murray, (2005). "Education Goes Digital: The Evolution of Online Learning and the Revolution in Higher Education," Communications of the ACM, October 2005, Volume 48, Number 10, pp. 59-64.

9. Jackson, Mary Jo, Helms, Marilyn M., (2008). "Student Perceptions of Hybrid Courses: Measuring and Interpreting Quality,” Washington: Journal of Education for Business, Sep/Oct, Volume 84, Number 1, pp. 7-12.

10. Millison, Murray R. and Wilemon, David (2008). "Educational Quality Correlates of Online Graduate Management Education," Journal of Distance Education, Volume 22, Number 3, pp. 1-18. 
11. Mosca, Joseph B., Ball, Daniel R., Buzza, John S., and Paul III, David P., (2010). “A Comprehensive Student-Based Analysis of Hybrid Courses: Student Preferences and Design Criteria for Success," Journal of Business \& Economics Research, May, Volume 8, Number 5, pp. 7-21.

12. Mossavar-Rahmani, Farhang, and Larson-Daugherty, Cynthia, (2007). "Supporting the Hybrid Learning Model: A New Proposition," MERLOT Journal of Online Learning and Teaching, March, Volume 3, Number 1, pp. 67-78.

13. Penrose, John, (2006). "Teaching The Essential Role Of Visualization In Preparing Instructions," Business Communication Quarterly, Volume 69, Number 4, pp. 411-417.

14. Peterson, Kenneth, Ponzio, Richard, Castori, Pamela, and Galloway, Robin, (2006). "Getting Creative With Assessments," Science and Children, Volume 43, Number 8, pp. 52-55.

15. Robinson, Sherry, and Ritzko, Jacqueline, (2009). "Podcasts in Education: What, Why, and How?" Proceedings of the Academy of Educational Leadership, Allied Academies International Conference, New Orleans, Volume 14, Number 1, pp. 38-43.

16. Rosebush, Judson, (1992). "Sounds in CD-ROM--Integrating Audio in Multimedia Products," CD-ROM Professional, January, Volume 5, Number 1, pp. 83-87.

17. Terry, Neil, (2007). "Assessing Instruction Models for Master of Business Administration (MBA) Courses," Washington: Journal of Education for Business, Mar/Apr 2007, Volume 82, Issue 4, pp. 220 225.

18. Valentine, Daniel, Hedrick, Mark S., and Swanson, Lori A., (2006). "Effect of an Auditory Training Program on Reading, Phoneme Awareness, and Language," Perceptual and Motor Skills, Aug, Volume 103, Issue 1, pp. 183-196.

19. Willems, Roel M., Ozyurek, Asli, and Hagoort, Peter, (2008). "Seeing and Hearing Meaning: ERP and fMRI Evidence of Word Versus Picture Integration Into a Sentence Context," Journal of Cognitive Neuroscience, July, Volume 20, Issue 7, pp. 1235-1249.

20. Yelon, Stephen, (2006), "Face-to-Face or Online? Choosing the Medium in Blended Training," Performance Improvement, Volume 45, Issue 3, pp. 22-26. 